\title{
Expression of human Kallikrein 14 (KLK|4) in breast cancer is associated with higher tumour grades and positive nodal status
}

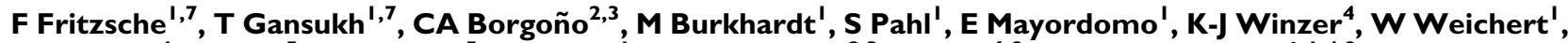

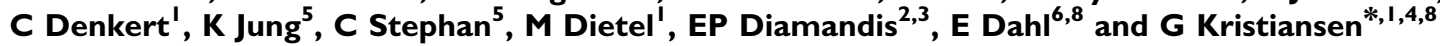

'Institute of Pathology, Department of Urology, Charité Universitätsmedizin, Berlin, Germany; ${ }^{2}$ Department of Pathology and Laboratory Medicine, Mount Sinai Hospital, Toronto, Canada; ${ }^{3}$ Department of Laboratory Medicine and Pathobiology, University of Toronto, Toronto, Canada; ${ }^{4}$ Breast Cancer Center, Charité Universitätsmedizin, Berlin, Germany; ${ }^{5}$ Department of Urology, Charité Universitätsmedizin, Berlin, Germany; ${ }^{6}$ nstitute of Pathology, University

Hospital of the RWTH Aachen, Aachen, Germany
\end{abstract}

Human kallikrein $14(K L K \mid 4)$ is a steroid hormone-regulated member of the tissue kallikrein family of serine proteases, for which a prognostic and diagnostic value in breast cancer has been suggested. To further characterise the value of KLKI4 as a breast tumour marker, we have carefully analysed KLKI 4 expression in normal breast tissue and breast cancer both on the RNA level by real-time RT-PCR ( $n=39)$, and on the protein level $(n=127)$ using a KLKI4-specific antibody for immunohistochemistry. We correlated KLKI 4 protein expression data with available clinico-pathological parameters (mean follow-up time was 55 months) including patient prognosis. KLK 4 RNA expression as quantified by real-time RT-PCR was significantly more abundant in breast tumours compared to normal breast tissue $(P=0.027)$, an issue that had not been clarified recently. Concordantly with the RNA data, cytoplasmic KLKI4 protein expression was significantly higher in invasive breast carcinomas compared to normal breast tissues $(P=0.003)$. Furthermore, KLKI4 protein expression was associated with higher tumour grade $(P=0.04 \mathrm{I})$ and positive nodal status $(P=0.045)$ but was not significantly associated with shortened disease-free or overall patient survival time in univariate analyses. We conclude that KLKI4 is clearly overexpressed in breast cancer in comparison to normal breast tissues and is positively associated with conventional parameters of tumour aggressiveness, but due to a missing association with survival times, the use of KLKI 4 immunohistochemistry as a prognostic marker in breast cancer is questionable.

British Journal of Cancer (2006) 94, 540-547. doi:I0.1038/sj.bjc.6602956 www.bjcancer.com

Published online 24 January 2006

(c) 2006 Cancer Research UK

Keywords: breast cancer; kallikrein; prognostic marker; immunohistochemistry; human kallikrein I4; serine protease

Human tissue kallikreins comprise a family of 15 secreted serine proteases, encoded by a multigene cluster (KLK genes) on chromosome 19q13.4 (Diamandis et al, 2000; Borgono et al, 2004; Clements et al, 2004). This family includes the most important serum tumour marker in clinical medicine for the early detection, risk stratification, clinical staging, and monitoring of prostate cancer, kallikrein 3 (KLK3), which is better known as prostate-specific antigen (PSA) (Diamandis, 1998). In recent years, many kallikreins in addition to KLK3/PSA, such as KLK2, KLK4, KLK5, KLK6, KLK7, KLK8, KLK9, KLK10, KLK11, KLK13, and KLK15 were found to be candidate biomarkers for several endocrine-related malignancies, including breast, ovarian and prostate cancers, demonstrating the immense clinical applicability of this family (Diamandis and Yousef, 2002; Borgono and Diamandis, 2004). With respect to breast cancer in particular, several kallikrein family members, namely KLK3 (Yu et al, 1996),

\footnotetext{
*Correspondence: Dr G Kristiansen; E-mail: glen.kristiansen@charite.de

${ }^{7}$ These authors contributed equally.

${ }^{8}$ Shared senior authorship.

Revised 30 November 2005; accepted 14 December 2005; published online 24 January 2006
}

KLK5 (Yousef et al, 2003c), KLK6 (Anisowicz et al, 1996), KLK10 (Liu et al, 1996; Dhar et al, 2001), KLK12 (Yousef et al, 2000b), KLK13 (Yousef et al, 2000a), and KLK14 (Borgono et al, 2003) were shown to be differentially expressed at the mRNA or protein levels within the cancerous tissues or serum of such patients. Furthermore, a number of preliminary analyses suggest that certain kallikreins including KLK3 (Yu et al, 1995; Yu et al, 1998; Foekens et al, 1999), KLK5 (Yousef et al, 2002b, 2003c; Diamandis et al, 2003), KLK7 (Talieri et al, 2004), KLK9 (Yousef et al, 2003a), KLK10 (Luo et al, 2002), KLK13 (Chang et al, 2002), KLK14 (Borgono et al, 2003), KLK15 (Yousef et al, 2002c) may possess clinical utility as diagnostic, prognostic or predictive breast cancer biomarkers. For recent reviews on the human kallikrein family please see references (Diamandis and Yousef, 2002; Borgono and Diamandis, 2004; Borgono et al, 2004; Clements et al, 2004).

Human kallikrein gene 14 (formerly known as KLK-L6) was cloned in 2001 via the positional candidate approach (Hooper et al, 2001; Yousef et al, 2001). The KLK14 gene is under steroid hormone regulation and is predominantly expressed in endocrine tissues (breast, prostate, ovary, testes) as detected on the mRNA and protein level (Yousef et al, 2001; Borgono et al, 2003; Yousef et al, 2003b, 2003d). A recent study by Borgono et al (2003) revealed that KLK14 protein levels are elevated in the serum of a 
proportion of patients with breast cancer, implicating KLK14 as a potential marker for breast cancer. However, conflicting data have been obtained regarding the question whether KLK14 is overexpressed in breast tumours compared to normal breast tissue. Although one study reported loss of KLK14 expression in 21 of 25 analysed breast tumours in comparison to normal breast tissue (Yousef et al, 2001), another study demonstrated abundant KLK14 expression in tumours and an association of high KLK14 expression with advanced disease (Yousef et al, 2002a). Thus, the presently available data leaves the question open whether KLK14 is a suitable biomarker for human breast cancer. Therefore, the main focus of the present study was to carefully and quantitatively analyse KLK14 protein expression in a large collection of human breast normal and tumour specimens to further evaluate the potential value of KLK14 for breast cancer prognosis.

\section{MATERIALS AND METHODS}

\section{Patients}

For immunohistochemistry, our study included 127 patients diagnosed with primary breast cancer at the Institute of Pathology, Charité Universitätsmedizin, Berlin, between 1991 and 1997. Patient age at the time of diagnosis ranged from 30 to 87 with a median of 57 years (mean 59). Follow-up data including overall survival and disease recurrence or progression times were available for all cases. The average observation time for overall survival was 55 months for patients still alive at the time of analysis, and ranged from 1 to 130 months. Twenty-two patients (17\%) died during follow-up and 43 patients (34\%) experienced disease progression defined by either metastatic or local recurrent disease.

Adjuvant therapy was administered as follows: The first group received either no or local therapy/radiotherapy (29 cases), or systemic therapy excluding tamoxifen (20 cases). The second group had received tamoxifen with or without an additional systemic or local therapy (70 cases). For eight patients, no data on adjuvant therapy was available.

The selection of cases for this study was based on availability of tissue. Cases were not stratified for any known preoperative or pathological prognostic factors. Cases with systemic disease (M1) at the time of diagnosis were excluded. Tumour histology was determined according to the criteria of the World Health Organization (Tavassoli and Devilee, 2003), whereas disease stage was assessed according to UICC (Wittekind et al, 2002). Tumours were graded according to Bloom and Richardson, as modified by Elston and Ellis (1993). Data regarding oestrogen receptor status and the expression of c-erbB2 were taken from archival pathology reports. Oestrogen receptor positivity was defined as an immunoreactive score (IRS) $>3$. Overexpression of c-erbB2 was defined according to the clinical trial assay $(2+, 3+)$ as recommended in the Hercep-test (DAKO). The clinicopathological characteristics of the patients/tumours are described in Table 1.

\section{RNA extraction from formalin-fixed paraffin-embedded breast normal and tumour tissue}

Archival formalin-fixed paraffin-embedded tissue from 25 breast cancer specimens and 14 normal breast tissue specimens were obtained from patients diagnosed at the Institute of Pathology of the University Hospital of Aachen, Germany. For each formalinfixed paraffin-embedded tissue specimen six $4-\mu \mathrm{m}$ thick tissue sections were cut with a microtome (Leica, Germany) and transferred to a water bath filled with DEPC-treated water. Sections were mounted on standard glass slides and dried for $1 \mathrm{~h}$ at $60^{\circ} \mathrm{C}$. Sections were deparaffinised and rehydrated as follows: $2 \times 15 \mathrm{~min}$ in xylene, $2 \times 15 \mathrm{~min}$ in $100 \%$ ethanol, and short rinses
Table I Clinicopathological parameters of the breast cancer patients

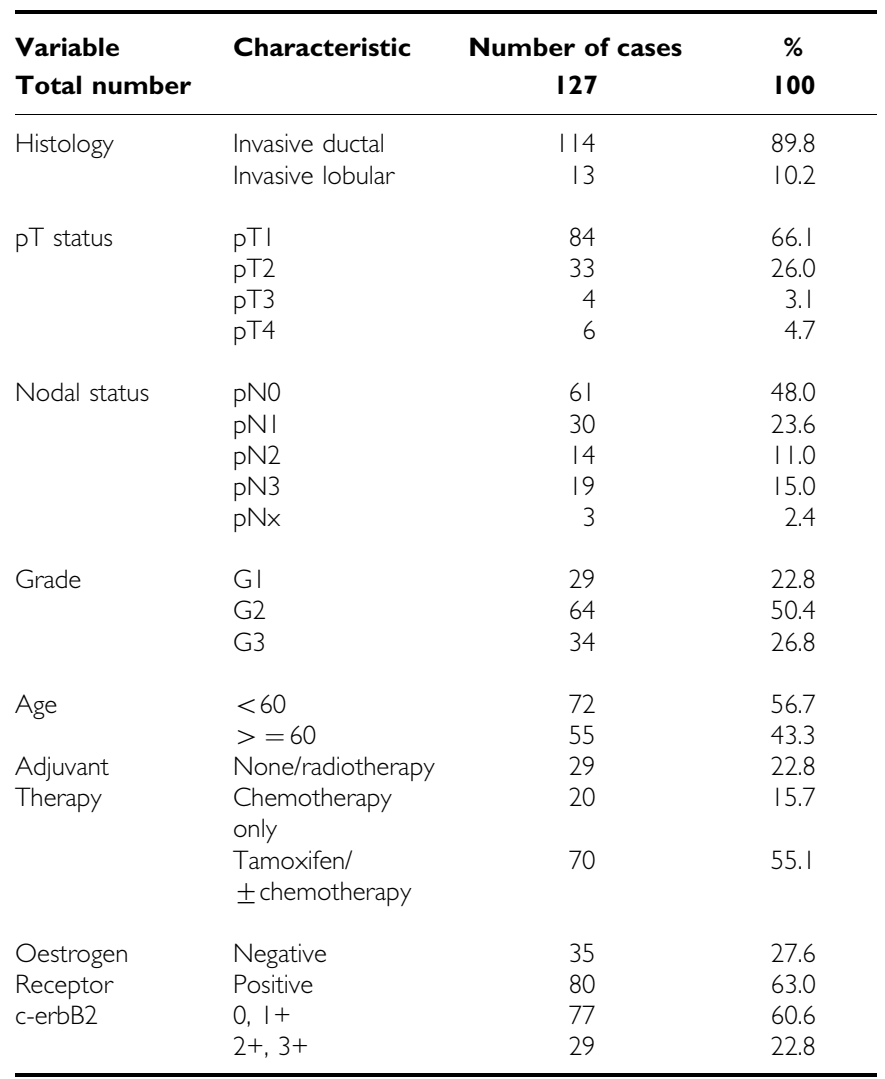

Table 2 Primers and probes used in real-time RT-PCR

\begin{tabular}{lll}
\hline Gene & Primer sequence & Product size \\
\hline KLKI4 & 5'-AGTGTCAGGCTGGGGAACTA-3' & $183 \mathrm{bp}$ \\
& 5'-CCCAGAGTCACCCTGACAAG-3' $^{\prime}$ & \\
$\beta$-Actin & 5-GGACGACATGGAGAAAATC-3' & $185 \mathrm{bp}$ \\
& 5-ATAGCACAGCCTGGATAGC-3' & \\
\hline
\end{tabular}

in 96,70 and $50 \%$ ethanol followed by emersion in distilled water. All tumour sections were manually microdissected to ensure a minimum of $80 \%$ tumour cells. Tissue material was transferred to a microcentrifuge tube and RNA was extracted according to the Trizol protocol supplied by the manufacturer (Life Technologies, Mannheim, Germany).

\section{Quantitative RT-PCR}

KLK14 mRNA-expression was analysed with the LightCycler ${ }^{\circledR}$ system (Roche Diagnostics, Germany) in archival formalin-fixed paraffin-embedded breast cancer and normal breast tissue specimens. $\beta$-Actin $m R N A$ was used as reference. Primers used in this study are presented in Table 2. Real-time RT-PCR was carried out with Fast Start DNA master hybridisation probes (Roche Molecular Biochemicals, Germany). The conditions were as follows: initial denaturation in one cycle of $15 \mathrm{~min}$ at $95^{\circ} \mathrm{C}$, followed by 40 cycles at $95^{\circ} \mathrm{C}$ for $20 \mathrm{~s}, 60^{\circ} \mathrm{C}$ ( $\beta$-Actin) or $62^{\circ} \mathrm{C}$ (KLK14) for $20 \mathrm{~s}$ and $72^{\circ} \mathrm{C}$ for $30 \mathrm{~s}$. Reaction, data acquisition and analysis were all performed by using the LightCycler ${ }^{\mathbb{R}}$ instrument. Gene expression was quantified by the comparative $C_{\mathrm{T}}$ method, 
normalizing $C_{\mathrm{T}}$-values to the housekeeping gene $\beta$-Actin and calculating the relative expression values of tumour and normal tissues (Fink et al, 1998).

\section{Anti-KLK14 antibody generation and cross-reactivity analysis}

Purified recombinant human Kallikrein $14(100 \mu \mathrm{g})$, produced as the mature enzyme form in the Pichia pastoris expression system as previously described (Felber et al, 2005), was used as an immunogen and injected s.c. into New Zealand White female rabbits for polyclonal antibody development. The protein was diluted 1:1 in complete Freund's adjuvant for the first injection and in incomplete Freund's adjuvant for subsequent injections. Injections were repeated six times at 3-week intervals. Blood was drawn from the animals and tested for antibody generation every 2 weeks.

Since KLK family proteins share $30-50 \%$ sequence similarity (Yousef and Diamandis, 2001), the potential crossreactivity of the $\alpha$-KLK14 polyclonal rabbit antibody to other KLKs was evaluated by Western blotting followed by densitometry of resultant bands. Briefly, natural (KLK3) or recombinant (KLK1, 2, 4-15) hK proteins produced in-house ( $100 \mathrm{ng}$ of KLK14; $1 \mu \mathrm{g}$ of other KLKs) were separated on $4-12 \%$ gradient polyacrylamide gels at $200 \mathrm{~V}$ for $30 \mathrm{~min}$ on the NuPAGE Bis-Tris electrophoresis system (Invitrogen, Carlsbad, CA, USA). Proteins were then transferred onto a Hybond-C extra nitrocellulose membrane (Amersham Biosciences, Piscataway, NJ, USA) at $30 \mathrm{~V}$ for $1 \mathrm{~h}$. The membrane was blocked in Tris-buffered saline-Tween $\left(0.1 \mathrm{moll}^{-1}\right.$ Tris- $\mathrm{HCl}$ buffer (pH 7.5) containing $0.15 \mathrm{moll}^{-1} \mathrm{NaCl}$ and $0.1 \%$ Tween 20 ) supplemented with $5 \%$ nonfat dry milk overnight at $4{ }^{\circ} \mathrm{C}$. The membrane was subsequently probed with the $\alpha$-KLK14 polyclonal rabbit antibody (diluted 1:2000 in Tris-buffered saline-Tween with $5 \%$ nonfat dry milk) for $1 \mathrm{~h}$ at room temperature. After washing the membrane three times for $15 \mathrm{~min}$ and three times for $5 \mathrm{~min}$ with Tris-buffered saline-Tween, it was treated with an alkaline phosphatase (ALP) conjugated goat anti-rabbit IgG antibody (1:20000 in Tris-buffered saline-Tween with 5\% milk; Jackson Immunoresearch Inc., Pennsylvania, PA, USA) for $1 \mathrm{~h}$ at room temperature. The membrane was washed again as above and ALP activity was detected on X-ray film using a chemiluminescent substrate (Diagnostic Products Corporation, Los Angeles, CA, USA). Developed films were scanned and resultant band intensities were analysed by semiquantitative densitometry with Labworks ${ }^{\mathrm{TM}}$ 4.0 Image Acquisition and Analysis Software (Ultra-Violet Products Ltd., Upland, CA, USA). The $\alpha$-KLK14 polyclonal rabbit antibody exhibited less than $1 \%$ crossreactivity at a 1:1 weight ratio between KLK14 and other KLKs (Figure 1).

\section{Immunohistochemistry}

Formalin-fixed paraffin embedded tissue was freshly cut $(4 \mu \mathrm{m})$. The sections were mounted on superfrost slides (Menzel Gläser, Braunschweig, Germany), dewaxed with xylene and gradually hydrated. Antigen retrieval was achieved by pressure cooking in $0.01 \mathrm{M}$ citrate buffer for $5 \mathrm{~min}$. The KLK14 antibody was diluted 1:1000 using a background reducing dilution buffer (DAKO, Hamburg, Germany). No other blocking agents were employed. The primary antibody was incubated at room temperature for $1 \mathrm{~h}$. As a negative control, four slides were processed without primary antibody. Detection was achieved by the conventional labelledstreptavidin-biotin (DAKO, Hamburg, Germany) method with ALP as the reporting enzyme according to the manufacturer's instructions. Fast-Red (Sigma-Aldrich, Munich, Germany) served as chromogen. Slides were briefly counterstained with haematoxylin and mounted.

\section{Evaluation of the immunohistochemical stainings}

The immunostainings were independently examined by three pathologists, who were blinded to patient outcome. The scoring system for KLK14 staining was relatively simple so as to minimize interobserver variability and enhance reproducibility in future studies. Invasive carcinoma, intraductal carcinoma and adjacent normal breast tissue were evaluated on each slide. We evaluated the cytoplasmic staining intensity of KLK14 together with the percentage of cells stained. An IRS was applied, as described by Remmele and Stegner (1987). The IRS is the product of staining intensity (graded between negative $=0$ and strong $=3$ ) and the percentage of positively stained cells (graded between 0 and 4, being $1=<25 \%, 2=25-50 \% ; 3=51-75 \%$, and $4=>75 \%$, respectively). Cases with discrepancies in IRS score among pathologists were discussed until consensus was reached.

\section{Statistical analysis}

The data were analysed with the software package SPSS, version 12.0 (SPSS Inc., Chicago, USA). In order to compare the delta CT values of the real-time RT-PCR results between specific groups the nonparametric Mann - Whitney $U$-test was used. Fisher's exact and $\chi^{2}$ tests for trends were used to assess the statistical significance of associations between KLK14 expression and clinico-pathological parameters. Bivariate correlations according to Spearman were applied to the IRS of normal tissue, intraductal and invasive carcinomas. Univariate survival analysis was performed according to Kaplan-Meier and differences in survival curves were assessed with the Log rank test. $P$-values $<0.05$ were considered significant.

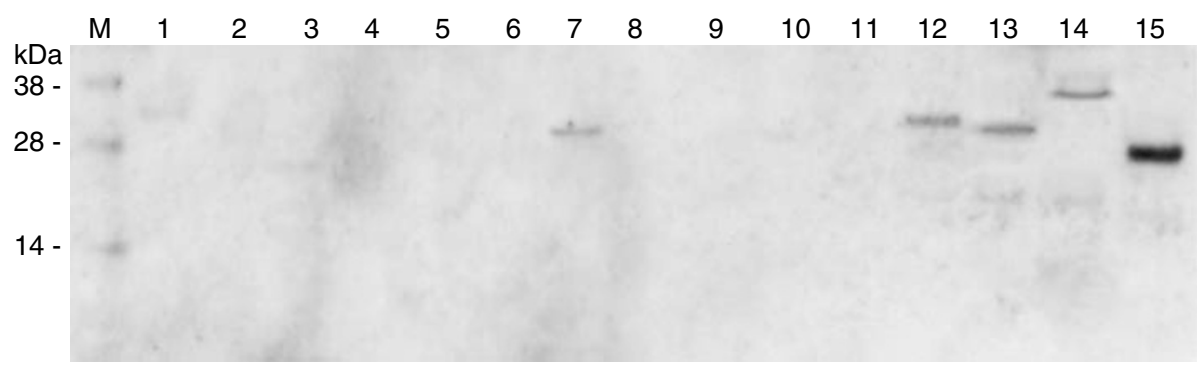

Figure I Specificity of the $\alpha$-KLKI 4 rabbit polyclonal antibody. Purified natural or recombinant KLKs I - I3 and I5 (| $\mu$ g; lanes I through I4, respectively) and recombinant KLKI4 (I00 ng; lane 15) were separated by SDS-PAGE, transferred to a nitrocellulose membrane and probed with $\alpha$-KLKI4 rabbit polyclonal antibody (I:2000). At this I: I 0 weight ratio between KLKI4 and other KLKs, this $\alpha$-KLKI 4 rabbit polyclonal antibody can weakly detect KLKs 7 , I2, 13 and 15 (lanes 7, 12, 13 and 14, respectively), as demonstrated by the relatively low intensity bands. This corresponded to < $1 \%$ crossreactivity at a I:I weight ratio between KLKI4 and other KLKs, as determined by semiquantitative densitometry. M, molecular weight marker. 


\section{RESULTS}

\section{Human kallikrein 14 (KLK14) mRNA expression}

KLK14 mRNA expression was analysed by LightCycler ${ }^{(\mathbb{R}}$ RT-PCR in a set of archival formalin-fixed paraffin-embedded tissue specimens, consisting of 25 primary breast cancer (14 from node-positive tumours, 11 from node-negative tumours) and 14 normal breast tissue samples. These data are presented in Figure 2. In $40 \%$ (10 out of 25 ) of the breast tumours analysed, we detected an at least two-fold upregulation in KLK14 mRNA expression compared to the mean KLK14 expression in normal breast tissue. Altogether, mean KLK14 mRNA expression in breast tumours was 2.3-fold more abundant compared to the mean expression of KLK14 mRNA in normal breast tissues; this difference was statistically significant $(P=0.027$, two-tailed Mann-Whitney $U$-test). In this data set no significant association was found between KLK14 expression level and histological grading, nodal status, tumour size or HER2, oestrogen and progesterone receptor status.

\section{Human kallikrein 14 immunostaining of breast tissue}

KLK14 was expressed in a weak to intermediate fashion in $91 \%$ of adjacent normal breast tissue (Figure 3A, Table 3). Intraductal carcinomas adjacent to the invasive tumour were present in 77 of the 127 cases. We observed cytoplasmic KLK14 expression in $99 \%$ of intraductal carcinomas (Figure 3B, Table 3) and in $96 \%$ of

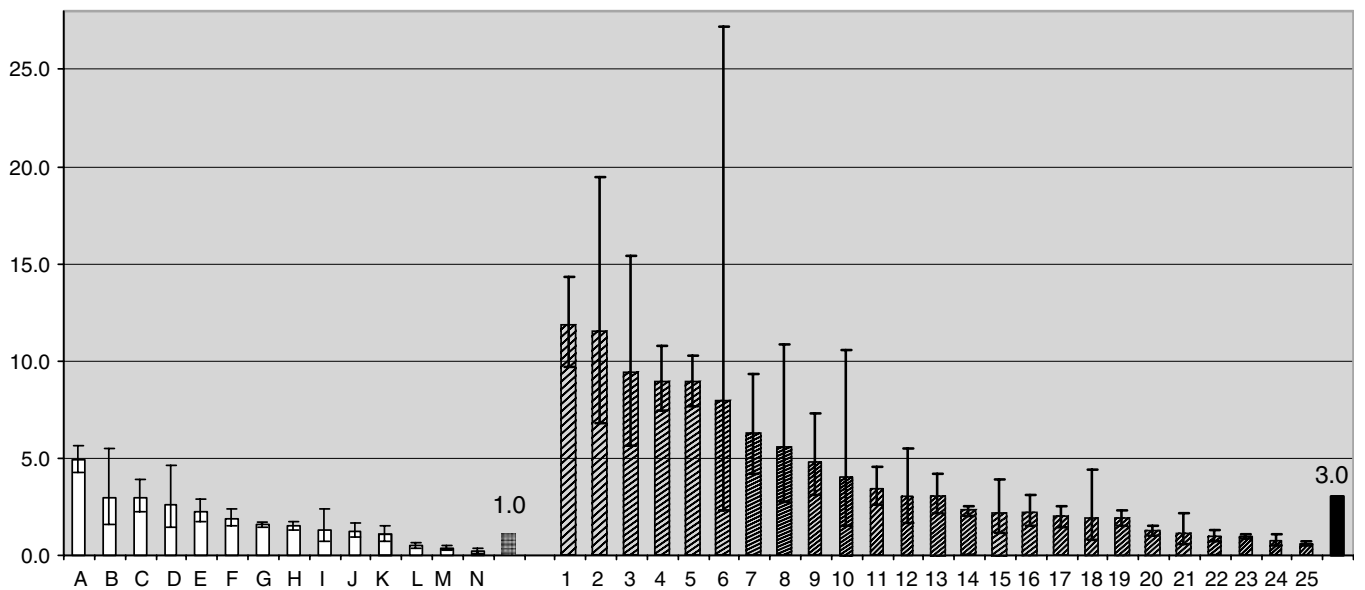

Figure 2 Diagrammatic presentation of quantitative RT-PCR data for KLKI4 mRNA from formalin-fixed paraffin-embedded breast cancer (samples $1-25$ ) and normal breast tissue specimens (samples A-N). Mean KLKI4 expression was 3.0-fold upregulated in breast tumours as compared to the mean expression in normal breast tissues (set equal to I).
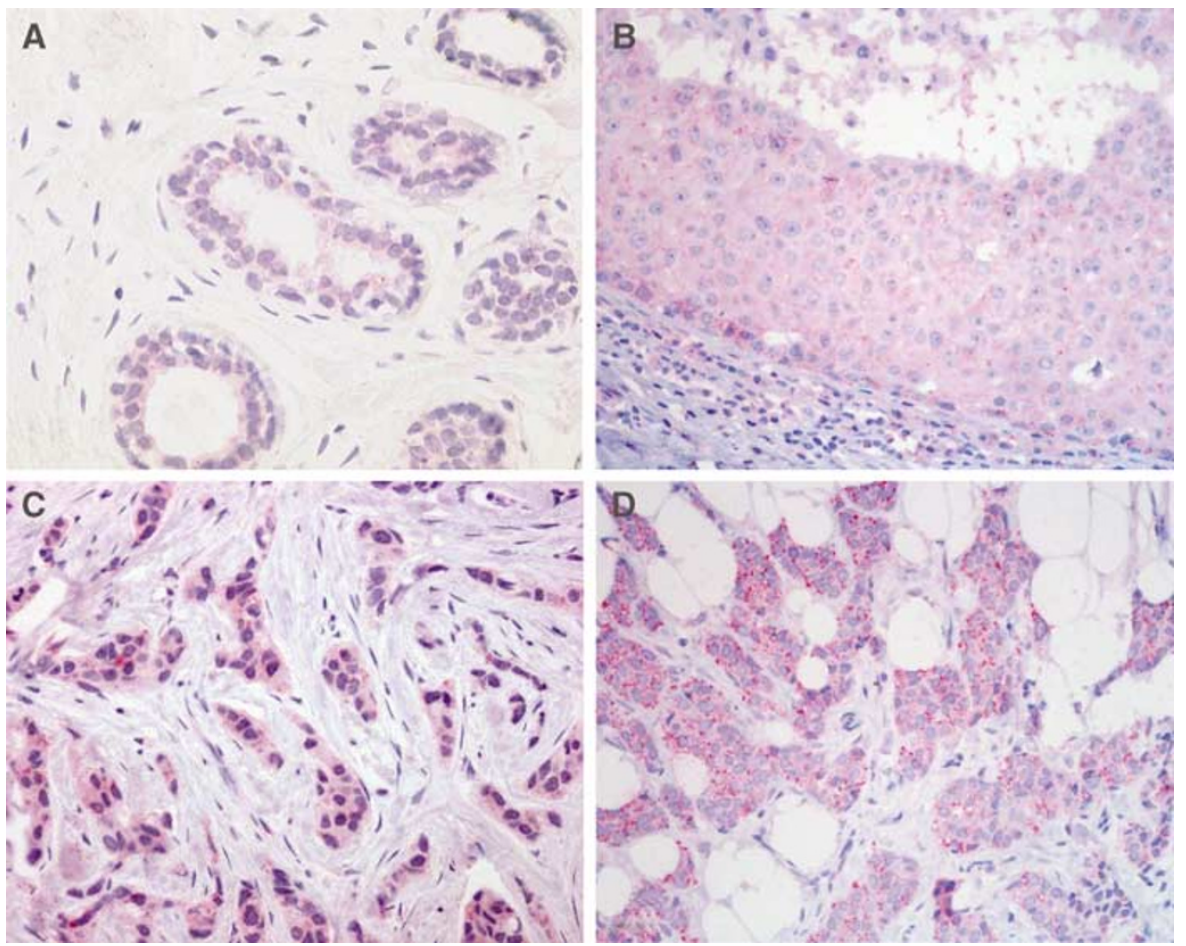

Figure $3 \mathrm{KLKI} 4$ immunohistochemistry in breast tissues. (A) Weak cytoplasmic immunoreactivity in secretory epithelia of normal lobular breast tissue. (B) Strong immunostaining of ductal carcinoma in situ. (C and D) Strong immunostaining in invasive ductal carcinomas with a diffuse cytoplasmic (C) and slightly granular pattern (D). 
Table 3 KLKI4 staining, immunoreactive score (IRS) and bivariate correlations in normal breast tissue, intraductal and invasive carcinoma

\begin{tabular}{|c|c|c|c|c|}
\hline Type of tissue & $\begin{array}{l}\text { Percentage of } \\
\text { tissue stained }(n)\end{array}$ & IRS median & IRS mean & $\begin{array}{l}\text { Correlation with } \\
\text { invasive carcinoma }\end{array}$ \\
\hline Normal breast $(n=127)$ & $91(115)$ & 2 & 2.9 & $\begin{array}{c}C C=0.361 \\
P<0.001\end{array}$ \\
\hline Intraductal carcinoma $(n=77)$ & $99(76)$ & 4 & 5.1 & $\begin{array}{l}C C=0.757 \\
P<0.001\end{array}$ \\
\hline Invasive carcinoma $(n=127)$ & $96(125)$ & 4 & 4.2 & \\
\hline
\end{tabular}

$C C=$ Correlation coefficient and $P=P$ value

Table 4 Associations between KLKI4 expression and clinical-pathological parameters

\begin{tabular}{|c|c|c|c|c|}
\hline \multirow[b]{2}{*}{ Variable } & \multirow[b]{2}{*}{ Patients } & \multicolumn{2}{|c|}{ No. of patients (\%) } & \multirow[b]{2}{*}{$P$-value } \\
\hline & & KLKI4 low & KLK I 4 high & \\
\hline Patient age & & & & 0.582 \\
\hline$<60$ years & 72 & $46(63.9)$ & $26(36.1)$ & \\
\hline$>=60$ years & 55 & $32(58.2)$ & $23(41.8)$ & \\
\hline Histology & & & & 0.246 \\
\hline Ductal & 114 & $72(63.2)$ & $42(36.8)$ & \\
\hline Lobular & 13 & $6(46.2)$ & $7(53.8)$ & \\
\hline pT status & & & & $0.323^{\mathrm{a}}$ \\
\hline pTI & 84 & $48(57.1)$ & $36(42.9)$ & \\
\hline PT2 & 33 & $24(72.7)$ & $9(27.3)$ & \\
\hline $\mathrm{PT} 3 / 4$ & 10 & $6(60.0)$ & $4(40.0)$ & \\
\hline PN status & & & & 0.045 \\
\hline pNO & 61 & $29(47.5)$ & $32(52.5)$ & \\
\hline $\mathrm{pNI}+$ & 64 & $19(29.7)$ & $45(70.3)$ & \\
\hline Histological grade & & & & 0.041 \\
\hline $\mathrm{GI} / 2$ & 93 & $41(44.1)$ & $52(55.9)$ & \\
\hline G3 & 34 & $8(23.5)$ & $26(76.5)$ & \\
\hline Oestrogen receptor & & & & 0.211 \\
\hline Negative & 35 & $10(28.6)$ & $25(71.4)$ & \\
\hline Positive & 80 & $34(42.5)$ & $46(57.5)$ & \\
\hline CerbB2 expression & & & & 1 \\
\hline $0,1+$ & 77 & $31(40.3)$ & $46(59.7)$ & \\
\hline $2+, 3+$ & 29 & II (37.9) & $18(62.1)$ & \\
\hline Therapy & & & & 0.563 \\
\hline None/local/CTx & 49 & $20(40.8)$ & $29(59.2)$ & \\
\hline Tamoxifen $\pm C T x$ & 70 & $24(34.3)$ & 46 (65.7) & \\
\hline
\end{tabular}

${ }^{a} \chi^{2}$ test for trends.

invasive carcinomas, respectively (Figure $3 \mathrm{C}$ and $\mathrm{D}$, Table 3 ), which was significantly stronger than in normal tissue $(P=0.003$, Fisher's exact test). The IRS score in adjacent normal tissue (median IRS $=2$ ), intraductal (median IRS $=4$ ) and invasive carcinomas (median IRS $=4$ ) was significantly correlated (all $P<0.001$, Table 3). This implies that cases with higher IRS scores in normal adjacent tissues were likely to have higher IRS scores in the tumour. To correct for interindividual staining qualities, we normalized the KLK14 immunoreactivity in carcinomas by subtracting the IRS of the normal tissue from the corresponding tumour IRS. Cases in which the tumour stained stronger than adjacent normal tissue (IRS $>=1$ ) were considered as tumours with high KLK14 expression. KLK14 was shown to be overexpressed in $61 \%$ (78 out of 127 cases) of invasive breast carcinomas compared to the adjacent normal breast tissues. In $18 \%$ (23 out of 127 cases) and 21\% (26 out of 127 cases) KLK14 expression was equal and higher in adjacent normal tissue compared to invasive carcinoma, respectively. There was a significant association of high KLK14 expression with higher tumour grade $(P=0.041)$ and positive nodal status $(P=0.045)$. KLK14 expression was not significantly associated with any other clinico-pathological parameters as shown in Table 4.

\section{Kallikrein 14 expression and survival}

Histological grade, tumour size and nodal status were significant predictors of both overall and disease-free survival (Tables 5-7). However, KLK14 expression was not associated with either disease-free or overall patient survival. Kaplan-Meier survival curves (Figure 4A and $\mathrm{B}$ ) indicate that patients with KLK14negative tumours tended to exhibit a slightly increased overall survival compared to patients with KLK14-positive tumours; however, these results did not reach statistical significance. As previous results related KLK14 to steroid response, we performed survival analyses for KLK14 expression stratified for oestrogen receptor status and endocrine therapy but did not find any significant results for neither disease-free or overall survival (data not shown).

\section{DISCUSSION}

In the present study, we carefully analysed KLK14 expression in normal and malignant breast tissue both on the RNA and protein level to further evaluate the potential value of KLK14 as a diagnostic marker in breast cancer. Using real-time RT-PCR we could clearly demonstrated KLK14 mRNA overexpression in breast cancer compared to normal breast tissue. These data are in conflict to a recent RT-PCR study, which showed loss of KLK14 expression in 21 of $25(84 \%)$ human breast cancer analysed (Yousef et al, 2001). However, our data are in agreement with another quantitative RT-PCR study that described much more abundant KLK14 expression (in 55 of 178 breast tumours) and a clear correlation of KLK14 expression and poor prognosis (Yousef $e t a l$, 2002a). The possible explanation for these disparities could be that our study and that of Yousef et al (2002a) used the more accurate quantitative RT-PCR technique.

The present study is the first to analyse KLK14 protein expression in a large cohort of human breast cancer specimens in comparison to matching normal breast tissues using a recently characterised KLK14-specific antibody (Felber et al, 2005). This KLK14 antibody demonstrated KLK14 protein overexpression in $61 \%$ of analysed tumour/normal tissue pairs. Next, we analysed the KLK14 protein expression data in relation to established prognostic indicators and patient survival and we found a significant correlation of KLK14 protein expression with tumor grade and nodal status. Currently oestrogen receptor- and cerbB2status represent the most important immunohistochemical diagnostic markers in breast cancer. Widely used, they provide clinically important information about the tumour biology and offer additional treatment options. This lead to a more individua- 
Table 5 Disease-free and overall survival according to clinicopathological variables and kallikrein I4 expression (univariate analysis)

\begin{tabular}{|c|c|c|c|c|c|c|c|c|}
\hline \multirow[b]{2}{*}{ Characteristic } & \multicolumn{4}{|c|}{ Disease-free survival } & \multicolumn{4}{|c|}{ Overall survival } \\
\hline & $\begin{array}{l}\text { No. of } \\
\text { cases }\end{array}$ & $\begin{array}{l}\text { No. of } \\
\text { events }\end{array}$ & $\begin{array}{c}\text { 5-year survival rate } \\
( \pm \text { s.e. })\end{array}$ & $P$-value & $\begin{array}{l}\text { No. of } \\
\text { cases }\end{array}$ & $\begin{array}{l}\text { No. of } \\
\text { events }\end{array}$ & $\begin{array}{c}\text { 5-year } \\
\text { nonprogression } \\
\text { rate }( \pm \text { s.e. })\end{array}$ & $P$-value \\
\hline KLK 14 expression & & & & 0.306 & & & & 0.602 \\
\hline Low & 49 & 18 & $64.5 \pm 6.9$ & & 49 & 7 & $89.0 \pm 4.4$ & \\
\hline High & 78 & 25 & $64.7 \pm 7.6$ & & 78 & 15 & $83.1 \pm 5.5$ & \\
\hline Age & & & & 0.163 & & & & 0.623 \\
\hline$<60$ years & 72 & 28 & $55.9 \pm 7.1$ & & 72 & 14 & $88.6 \pm 4.1$ & \\
\hline$>=60$ years & 55 & 15 & $77.3 \pm 6.1$ & & 55 & 8 & $86.8 \pm 5.1$ & \\
\hline Histology & & & & 0.929 & & & & 0.856 \\
\hline Ductal & 114 & 39 & $61.2 \pm 15.8$ & & 114 & 20 & $86.0 \pm 3.7$ & \\
\hline Lobular & 13 & 4 & $65.1 \pm 5.3$ & & 13 & 2 & $90.9 \pm 8.7$ & \\
\hline pT status & & & & 0.001 & & & & 0.001 \\
\hline pTI & 84 & 21 & $76.9 \pm 5.4$ & & 84 & 6 & $94.6 \pm 2.6$ & \\
\hline pT2 & 33 & 18 & $33.4 \pm 11.1$ & & 33 & | | & $75.2 \pm 9.0$ & \\
\hline $\mathrm{PT} 3 / 4$ & 10 & 4 & $60.0 \pm 15.5$ & & 10 & 5 & $60.0 \pm 19.3$ & \\
\hline Nodal status & & & & 0.0295 & & & & 0.001 \\
\hline PNO & 61 & 13 & $78.5 \pm 6.3$ & & 61 & 2 & $96.2 \pm 2.6$ & \\
\hline $\mathrm{PNI}+$ & 64 & 28 & $55.1 \pm 7.3$ & & 64 & 20 & $77.7 \pm 5.7$ & \\
\hline Histological grade & & & & 0.0155 & & & & 0.043 \\
\hline $\mathrm{Gl} / 2$ & 93 & 12 & $72.9 \pm 5.5$ & & 93 & 12 & $89.9 \pm 3.7$ & \\
\hline G3 & 34 & 10 & $41.4 \pm 10.4$ & & 34 & 10 & $77.5 \pm 7.5$ & \\
\hline Oestrogen receptor & & & & 0.7379 & & & & 0.379 \\
\hline Negative & 35 & 12 & $67.2 \pm 8.8$ & & 35 & 9 & $84.8 \pm 6.3$ & \\
\hline Positive & 80 & 27 & $64.5 \pm 6.6$ & & 80 & 12 & $85.2 \pm 4.6$ & \\
\hline c-erbB2 expression & & & & 0.394 & & & & 0.301 \\
\hline $0,1+$ & 77 & 24 & $71.8 \pm 6.4$ & & 77 & 12 & $87.0 \pm 4.3$ & \\
\hline $2+, 3+$ & 29 & 11 & $56.4 \pm 10.1$ & & 29 & 6 & $84.3 \pm 7.2$ & \\
\hline
\end{tabular}

Table 6 Cox univariate and multivariate analysis for disease-free survival. Variables were grouped according to Tables 4 and 5

\begin{tabular}{lccr}
\hline Variable & $\begin{array}{c}\text { Relative } \\
\text { risk }\end{array}$ & $\begin{array}{c}\text { Confidence } \\
\text { interval (95\%) }\end{array}$ & P-value \\
\hline $\begin{array}{l}\text { Univariate analysis } \\
\text { Kallikrein 14 }\end{array}$ & 1.370 & $0.746-2.517$ & 0.310 \\
PT status & 1.441 & $1.044-1.990$ & 0.026 \\
Nodal status & 2.479 & $1.450-4.237$ & 0.001 \\
Histological grade & 2.539 & $1.543-4.178$ & $<0.001$ \\
& & & 0.103 \\
Multivariate analysis & & & 0.536 \\
Kallikrein |4 & 0.572 & $0.292-1.119$ & 0.070 \\
PT status & 0.845 & $0.495-1.442$ & 0.041 \\
Nodal status & 2.078 & $0.942-4.584$ & \\
Histological grade & 2.159 & $1.033-4.514$ & \\
\hline
\end{tabular}

lized cancer therapy with antihormonal drugs or trastuzumab antibody (Fuqua and Cui, 2002; Bell et al, 2004), both of which improved patient outcome in selected patient cohorts. It remains to be focus of further study, whether KLK14 offers independent additional information in breast cancer or if KLK14 could be a potential target of specific therapy.

An earlier study by Yousef et al (2002a) examined the prognostic value of KLK14 expression in 178 breast cancer on the RNA level and found that high KLK14 mRNA expression was associated with advanced stage (III) disease. KLK14 also was an independent predictor of decreased disease-free and overall
Table 7 Cox univariate and multivariate analysis for overall-free survival. Variables were grouped according to Tables 4 and 5

\begin{tabular}{lccc}
\hline Variable & $\begin{array}{c}\text { Relative } \\
\text { risk }\end{array}$ & $\begin{array}{c}\text { Confidence } \\
\text { interval (95\%) }\end{array}$ & P-value \\
\hline Univariate analysis & & & \\
$\quad$ Kallikrein 14 & 1.269 & $0.516-3.120$ & 0.604 \\
$\quad$ PT status & 2.150 & $1.394-3.316$ & 0.001 \\
$\quad$ Nodal status & 4.313 & $1.654-11.250$ & 0.003 \\
$\quad$ Histological grade & 2.521 & $1.265-5.022$ & 0.009 \\
Multivariate analysis & & & \\
$\quad$ Kallikrein 14 & 1.107 & $0.407-3.013$ & 0.843 \\
$\quad$ PT status & 1.611 & $0.820-3164$ & 0.166 \\
$\quad$ Nodal status & 4.434 & $0.889-22.106$ & 0.069 \\
$\quad$ Histological grade & 1.391 & $0.512-3.777$ & 0.517 \\
\hline
\end{tabular}

survival. The cutoff value in this study (Yousef et al, 2002a) for KLK14 positive and negative tumours was defined by its ability to predict disease-free and overall survival and resulted in the definition of KLK14 positivity in $31 \%$ of breast tumours. In our study, we decided to use the median of KLK14 expression to delineate groups of low and high expression levels. With this cutoff value a significant association between KLK14 and tumour grading and positive nodal status was shown, both of which are indicators of a more aggressive course of disease. Alterations in the cutoff values to adapt the KLK14 postitive/negative ratio to the aforementioned study did not lead to any significant results (data not shown). 

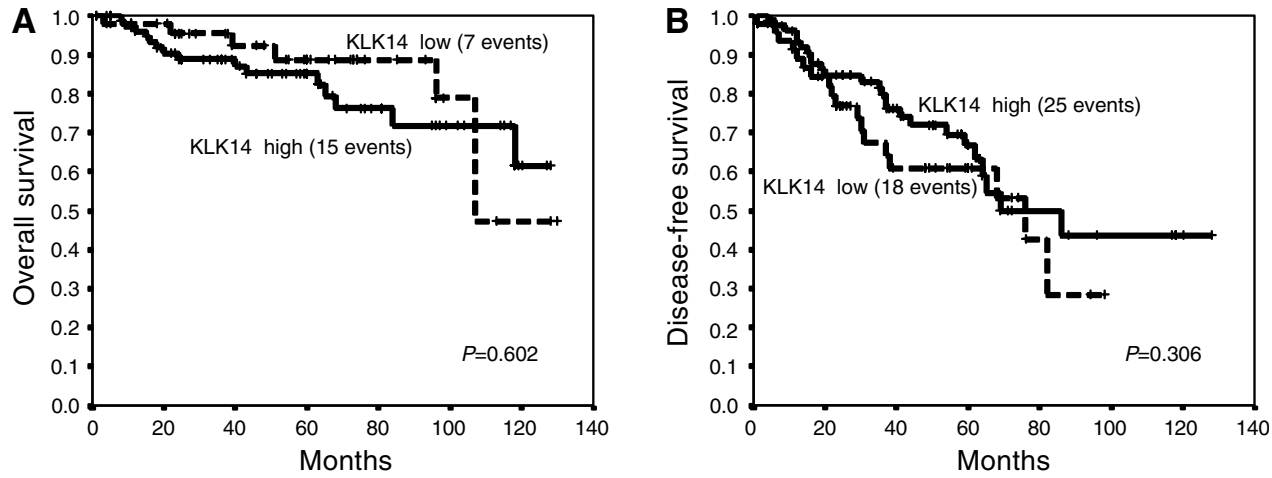

Figure 4 Univariate survival curves (Kaplan-Meier) for overall $(\mathbf{A})$ and disease-free (B) survival according to high (bold line) versus low (dotted line) KLKI4 expression. The number patients in the high and the low expression group were 78 and 49, respectively. The number of events in each group is stated in brackets.

Borgono et al (2003) have previously proposed that KLK14 may represent a new biomarker for breast cancer, having shown KLK14 serum levels to be elevated in eight out of $20(40 \%)$ breast cancer patients. This equals the KLK14 elevation in breast cancer tissues we observed in 40 and $61 \%$ of cases on RNA and protein level, respectively, and thus may account for the KLK14 elevation in the serum of a proportion of breast cancer patients.

Although the potential pathobiological role of KLK14 in breast cancer has not been elucidated, several lines of evidence suggest that KLK14, like many other kallikreins, may be causally involved in breast tumour progression (Borgono and Diamandis, 2004; Felber et al, 2005). This is substantiated by the fact that KLK14, via its serine protease activity, is able to degrade components of the extracellular matrix, including collagen IV $\alpha 1$ chain, collagen XII and matrilin-4 in vitro, which may promote tumour cell invasion and metastasis in vivo (Felber et al, 2005). These findings may have

\section{REFERENCES}

Anisowicz A, Sotiropoulou G, Stenman G, Mok SC, Sager R (1996) A novel protease homolog differentially expressed in breast and ovarian cancer. Mol Med 2: 624-636

Bell R, Verma S, Untch M, Cameron D, Smith I (2004) Maximizing clinical benefit with trastuzumab. Semin Oncol 31: 35-44

Borgono CA, Diamandis EP (2004) The emerging roles of human tissue kallikreins in cancer. Nat Rev Cancer 4: 876-890

Borgono CA, Grass L, Soosaipillai A, Yousef GM, Petraki CD, Howarth DH, Fracchioli S, Katsaros D, Diamandis EP (2003) Human kallikrein 14: new potential biomarker for ovarian and breast cancer. Cancer Res 63: 9032-9041

Borgono CA, Michael IP, Diamandis EP (2004) Human tissue kallikreins: physiologic roles and applications in cancer. Mol Cancer Res 2: 257-280

Chang A, Yousef GM, Scorilas A, Grass L, Sismondi P, Ponzone R, Diamandis EP (2002) Human kallikrein gene 13 (KLK13) expression by quantitative RT-PCR: an independent indicator of favourable prognosis in breast cancer. Br J Cancer 86: $1457-1464$

Clements JA, Willemsen NM, Myers SA, Dong Y (2004) The tissue kallikrein family of serine proteases: functional roles in human disease and potential as clinical biomarkers. Crit Rev Clin Lab Sci 41: $265-312$

Dhar S, Bhargava R, Yunes M, Li B, Goyal J, Naber SP, Wazer DE, Band V (2001) Analysis of normal epithelial cell specific-1 (NES1)/Kallikrein 10 mRNA expression by in situ hybridization, a novel marker for breast cancer. Clin Cancer Res 7: $3393-3398$

Diamandis EP (1998) Prostate-specific antigen-its usefulness in clinical medicine. Trends Endocrinol Metab 9: 310-316

Diamandis EP, Borgono CA, Scorilas A, Yousef GM, Harbeck N, Dorn J, Schmalfeldt B, Schmitt M (2003) Immunofluorometric quantification of human kallikrein 5 expression in ovarian cancer cytosols and its therapeutic applications by targeting KLK14 in appropriate patients.

In conclusion, although our data provides further evidence to support the association of KLK14 with aggressive breast cancer, immunohistochemically determined KLK14 expression in primary breast cancer does not appear to have additional prognostic value for the surgical pathologist. Further basic and clinical studies are warranted to clarify the potential role of KLK14 in the progression of breast cancer.

\section{ACKNOWLEDGEMENTS}

We are grateful to Britta Beyer and Inge Losen for excellent technical assistance and Ilka Olson for helpful discussions.

association with unfavorable patient prognosis. Tumour Biol 24: 299-309

Diamandis EP, Yousef GM (2002) Human tissue kallikreins: a family of new cancer biomarkers. Clin Chem 48: 1198-1205

Diamandis EP, Yousef GM, Clements J, Ashworth LK, Yoshida S, Egelrud T, Nelson PS, Shiosaka S, Little S, Lilja H, Stenman UH, Rittenhouse HG, Wain H (2000) New nomenclature for the human tissue kallikrein gene family. Clin Chem 46: $1855-1858$

Elston EW, Ellis IO (1993) Method for grading breast cancer. J Clin Pathol 46: $189-190$

Felber LM, Borgono CA, Cloutier SM, Kundig C, Kishi T, Ribeiro CI, Jichlinski P, Gygi CM, Leisinger HJ, Diamandis EP, Deperthes D (2005) Enzymatic profiling of human kallikrein 14 using phage-display substrate technology. Biol Chem 386: $291-298$

Fink L, Seeger W, Ermert L, Hanze J, Stahl U, Grimminger F, Kummer W, Bohle RM (1998) Real-time quantitative RT-PCR after laser-assisted cell picking. Nat Med 4: 1329-1333

Foekens JA, Diamandis EP, Yu H, Look MP, Meijer-van Gelder ME, van Putten WL, Klijn JG (1999) Expression of prostate-specific antigen (PSA) correlates with poor response to tamoxifen therapy in recurrent breast cancer. Br J Cancer 79: $888-894$

Fuqua SA, Cui Y (2002) Targeting the estrogen receptor in clinical breast cancer. Breast Dis 15: 3-11

Hooper JD, Bui LT, Rae FK, Harvey TJ, Myers SA, Ashworth LK, Clements JA (2001) Identification and characterization of KLK14, a novel kallikrein serine protease gene located on human chromosome 19q13.4 and expressed in prostate and skeletal muscle.. Genomics 73: 117-122

Liu XL, Wazer DE, Watanabe K, Band V (1996) Identification of a novel serine protease-like gene, the expression of which is down-regulated during breast cancer progression. Cancer Res 56: $3371-3379$ 
Luo LY, Diamandis EP, Look MP, Soosaipillai AP, Foekens JA (2002) Higher expression of human kallikrein 10 in breast cancer tissue predicts tamoxifen resistance. Br J Cancer 86: $1790-1796$

Remmele W, Stegner HE (1987) Recommendation for uniform definition of an immunoreactive score (IRS) for immunohistochemical estrogen receptor detection (ER-ICA) in breast cancer tissue. Pathologe 8: $138-140$

Talieri M, Diamandis EP, Gourgiotis D, Mathioudaki K, Scorilas A (2004) Expression analysis of the human kallikrein 7 (KLK7) in breast tumors: a new potential biomarker for prognosis of breast carcinoma. Thromb Haemost 91: $180-186$

Tavassoli FA, Devilee P (2003) World Health Organization Classification of Tumours. Pathology and Genetics of Tumours of the Breast and Female Genital Organs. Lyon: IARC Press

Wittekind Ch, Meyer HJ, Bootz F (2002) TNM Classification of Malignant Tumours. NewYork: Wiley-Liss, Inc.

Yousef G, Scorilas A, Nakamura T, Ellatif MA, Ponzone R, Biglia N, Maggiorotto F, Roagna R, Sismondi P, Diamandis E (2003a) The prognostic value of the human kallikrein gene 9 (KLK9) in breast cancer. Breast Cancer Res Treat 78: $149-158$

Yousef GM, Borgono CA, Scorilas A, Ponzone R, Biglia N, Iskander L, Polymeris ME, Roagna R, Sismondi P, Diamandis EP (2002a) Quantitative analysis of human kallikrein gene 14 expression in breast tumours indicates association with poor prognosis. $\mathrm{Br} J$ Cancer 87: $1287-1293$

Yousef GM, Chang A, Diamandis EP (2000a) Identification and characterization of KLK-L4, a new kallikrein-like gene that appears to be downregulated in breast cancer tissues. J Biol Chem 275: $11891-11898$

Yousef GM, Diamandis EP (2001) The new human tissue kallikrein gene family: Structure, function, and association to disease. Endocrine Reviews 22: $184-204$

Yousef GM, Fracchioli S, Scorilas A, Borgono CA, Iskander L, Puopolo M, Massobrio M, Diamandis EP, Katsaros D (2003b) Steroid hormone regulation and prognostic value of the human kallikrein gene 14 in ovarian cancer. Am I Clin Pathol 119: 346-355
Yousef GM, Magklara A, Chang A, Jung K, Katsaros D, Diamandis EP (2001) Cloning of a new member of the human kallikrein gene family, KLK14, which is down-regulated in different malignancies. Cancer Res 61: $3425-3431$

Yousef GM, Magklara A, Diamandis EP (2000b) KLK12 is a novel serine protease and a new member of the human kallikrein gene familydifferential expression in breast cancer. Genomics 69: $331-341$

Yousef GM, Polymeris ME, Grass L, Soosaipillai A, Chan PC, Scorilas A, Borgono C, Harbeck N, Schmalfeldt B, Dorn J, Schmitt M, Diamandis EP (2003c) Human kallikrein 5: a potential novel serum biomarker for breast and ovarian cancer. Cancer Res 63: 3958-3965

Yousef GM, Scorilas A, Kyriakopoulou LG, Rendl L, Diamandis M, Ponzone R, Biglia N, Giai M, Roagna R, Sismondi P, Diamandis EP (2002b) Human kallikrein gene 5 (KLK5) expression by quantitative PCR: an independent indicator of poor prognosis in breast cancer. Clin Chem 48: $1241-1250$

Yousef GM, Scorilas A, Magklara A, Memari N, Ponzone R, Sismondi P, Biglia N, Abd Ellatif M, Diamandis EP (2002c) The androgen-regulated gene human kallikrein 15 (KLK15) is an independent and favourable prognostic marker for breast cancer. Br J Cancer 87: 1294-1300

Yousef GM, Stephan C, Scorilas A, Ellatif MA, Jung K, Kristiansen G, Jung M, Polymeris ME, Diamandis EP (2003d) Differential expression of the human kallikrein gene 14 (KLK14) in normal and cancerous prostatic tissues. Prostate 56: $287-292$

Yu H, Diamandis EP, Levesque M, Giai M, Roagna R, Ponzone R, Sismondi P, Monne M, Croce CM (1996) Prostate specific antigen in breast cancer, benign breast disease and normal breast tissue. Breast Cancer Res Treat 40: $171-178$

Yu H, Giai M, Diamandis EP, Katsaros D, Sutherland DJ, Levesque MA, Roagna R, Ponzone R, Sismondi P (1995) Prostate-specific antigen is a new favorable prognostic indicator for women with breast cancer. Cancer Res 55: $2104-2110$

Yu H, Levesque MA, Clark GM, Diamandis EP (1998) Prognostic value of prostate-specific antigen for women with breast cancer: a large United States cohort study. Clin Cancer Res 4: 1489-1497 